\title{
Perancangan Komik Digital Untuk Mempromosikan 30 Ikon Kuliner Nusantara
}

\author{
Surya Bagus Sasongko Jati dan Rabendra Yudistira Alamin \\ Departemen Desain Produk, Fakultas Arsitektur Desain dan Perencanaan, \\ Institut Teknologi Sepuluh Nopember (ITS) \\ e-mail: okisurya70@gmail.com
}

\begin{abstract}
Abstrak-Indonesia terkenal di mata dunia sebagai negara dengan beragam kebudayaan dan ribuan kepulauan. Karena keberagaman tersebut, ragam jenis masakan muncul dengan jumlah mencapai ribuan, bahkan lebih. Melalui potensi tersebut terdapat peluang untuk mengembangkan salah satu sub sektor Pariwisata Indonesia, yaitu Pariwisata kuliner. Pariwisata kuliner sebelumnya telah dipromosikan oleh Kementerian Pariwisata guna memperkenalkan masakan Indonesia, yaitu dengan mencanangkan 30 nama Ikon Kuliner Nusantara yang akan menjadi wajah Pariwisata kuliner Indonesia di mata internasional. Selain menjadi wajah Pariwisata kuliner Indonesia, dilaksanakannya program tersebut bertujuan untuk meningkatkan kesadaran masyarakat mancanegara akan keragaman makanan yang ada di Indonesia. Media promosi yang akan digunakan dalam perancangan ini adalah media komik, komik dipilih karena media ini dapat menjelaskan informasi serta cerita secara sekuensial dengan menggunakan panel, dalam perancangan ini tipe dari komik yang akan digunakan adalah komik digital. Komik digital dipilih karena dapat memudahakan pendistribusian dari komik 30 Ikon Kuliner kepada pembaca dari mancanegara, konsep dari komik akan menceritakan cara memasak, bahan serta cerita dibalik tiap ikon kuliner dengan menggunakan komik tipe Vertikal kontinyu. Luaran dari perancangan ini akan berupa komik yang dapat menyajikan informasi yang deskriptif serta informatif tentang ke 30 Ikon Kuliner Nusantara.
\end{abstract}

Kata Kunci- kuliner, pariwisata, komik digital.

\section{PENDAHULUAN}

$\mathrm{I}_{\mathrm{N}}^{\mathrm{s}}$ NDONESIA terkenal di mata dunia sebagai negara dengan ribuan kepulauan, ratusan suku dan bermacam kepercayaan dan keberagaman. Dari situ lahirlah berbagai macam masakan khas daerah dengan jumlah sekitar 5300 jenis masakan. Kepala Badan tim Percepatan dari Kementerian Pariwisata, Vita Datau, berkeinginan meningkatkan jumlah wisatawan mancanegara dengan target 20 juta pengunjung dalam kurun waktu 2 tahun. Hal tersebut dapat tercapai melalui pengembangan di bidang Pariwisata Kuliner.

Salah satu program Pariwisata Kuliner yang dilakukan pada Desember 2013 oleh Kementerian Pariwisata adalah mencanangkan 30 Ikon Kuliner Nusantara, yang akan menjadi wajah Pariwisata kuliner Indonesia di mata internasional. Selain untuk mendorong jumlah pengunjung, dijalankannya program tersebut bertujuan meningkatkan kesadaran masyarakat mancanegara akan keragaman makanan yang ada di Indonesia.

Lima tahun program ini sudah berjalan dan terdapat beberapa strategi promosi yang telah dilakukan Kementerian
Pariwisata dalam mensosialisasikan program ini seperti; festival kuliner internasional dan nasional serta sosialisasi resep masakan di sekolah perhotelan, mengetahui fakta tersebut, ada baiknya Kementerian Pariwisata mulai mempertimbangkan pengembangan di bidang promosi melalui media lain, terutama dalam mengikuti perkembangan media. Strategi promosi dalam mengiklankan sebuah produk yang saat ini sering digunakan adalah promosi melalui Penuturan atau Storytelling.

Salah satu media yang tepat dalam mengaplikasikan penuturan atau storytelling ke dalam subjek desain adalah komik, terutama jenis dari komik yang saat ini sedang mendapat sorotan publik, yaitu komik digital. Komik sendiri adalah media visual dimana gambar demi gambar disandingkan membentuk sebuah sekuen yang dimaksudkan untuk menarasikan dan menyampaikan sebuah informasi[1].

Komik kemudian dipilih karena media ini memiliki beberapa kelebihan seperti; Komik dapat menunjukkan bagaimana sesuatu bekerja, memiliki kesan penceritaan yang personal dan dapat memberikan visualisasi akan penjelasan yang abstrak. Sedangkan pemilihan komik dalam bentuk digital adalah salah satu cara dalam mempenetrasi pasar internasional, karena kebanyakan distributor komik digital saat ini menggunakan portal baca berupa website yang didistribusikan di tiap negara besar, contohnya seperti Line Webtoon dan juga Lezhin Comic, yang membuat portal baca di China, Amerika, Eropa, Thailand serta Indonesia. Dengan terbukanya peluang tersebut komik ini dapat mencapai target audien yang disasar yaitu audien dari mancanegara.

Diharapkan dengan adanya komik digital, program 30 Ikon Kuliner Nusantara dapat menembus pasar internasional dan dapat menjadi komik yang mampu menceritakan serta mempromosikan keragaman kuliner Indonesia dengan deskriptif dan informatif melalui media komik digital untuk wisatawan manca negara dan domestik.

\section{A. Identifikasi Masalah}

1. Sulitnya mengidentifikasi mana yang termasuk masakan asli indonesia.

2. Perlunya Pengembangan jalur dan media promosi dari program 30 Ikon Kuliner Nusantara.

3. Sisi storytelling dari program 30 Ikon Kuliner Nusantara belum dikembangkan ke media manapun.

\section{B. Rumusan Masalah}

"Bagaimana merancang komik digital yang mampu mempresentasikan ragam kuliner yang dicanangkan 
pemerintah untuk wisatawan domestik dan manca negara yang deskriptif dan informatif?“

\section{C.Batasan Masalah}

1. Konten makanan yang tampil dalam komik mengikuti sumber buku 30 ikon kuliner nusantara.

2. Komik digital hanya menjelaskan secara garis besar mengenai masakan, baik bahan maupun cara memasak.

3. Gambar yang ada dalam komik terbatas pada bentuk penggambaran dari studi yang telah dilakukan penulis.

\section{D.Tujuan}

1. Mengenalkan keberagaman kuliner tradisional indonesia pada audien mancanegara.

2. Meningkatkan promosi dari pariwisata kuliner indonesia melalui media penuturan

3. Mampu mendokumentasikan secara deskriptif dan informatif dari 30 nama masakan yang sudah diangkat oleh pemerintah.

\section{II.METODE PENELITIAN}

\section{A. Metodologi Penelitian}

\section{1) Depth Interview}

Wawancara mendalam dilakukan kepada beberapa narasumber yang terkait dengan program 30 ikon. Ibu Ernawati dan Ibu Agustin selaku pengurus program serta Praktisi di bidang komik, Is Yuniarto. Tujuan daripada wawancara ini untuk mengetahui lebih dalam mengenai program serta untuk mengetahui perkembangan terkini dari dunia perkomikan digital.

\section{2) Studi Literatur}

Metode berikut dilakukan guna mempelajari lebih lanjut mengenai program 30 ikon, dunia kuliner serta media komik, berikut adalah beberapa literasi yang digunakan:
a. Buku masak "30 Ikon Kuliner Nusantara"
b. Buku "Antroplogi Kuliner Indonesia"
c. Buku "Jejak Rasa Nusantara"
d. Buku komik "Masak Dirumah Yuk"
e. Komik Digital "Jajan Squad"
f. Buku "Universal Methods of Design"

\section{3) Kuesioner}

Kuesioner bertujuan untuk mengetahui dan mendapatkan data secara kuantitatif dengan memberikan pertanyaan mengenai subjek desain perancangan kepada responden dari mancanegara. Data yang akan didapat diantaranya:
a. Tanggapan responden akan masakan indonesia
b. Tingkat ketertarikan responden untuk mengenal kuliner indonesia
c. Tanggapan responden akan media komik digital

\section{HASIL PENELITIAN}

\section{A. Hasil Penelitian}

Dari penelitian yang telah dilakukan berikut adalah beberapa poin utama yang digunakan sebagai bahan pengambilan keputusan dalam merancang konsep dan kriteria dari komik digital diantaranya:

1) Depth Interview (Ibu Agustin dan Ibu Ernawati)

a. Target utama dari program ini adalah wisatawan mancanegara dan juga domestik.

b. Tujuan utama program ini yaitu diplomasi kuliner dengan negara lain, dokumentasi lengkap tiap makanan dan meningkatkan jumlah wisatawan di destinasi pariwisata seperti Solo, Bandung dan Yogyakarta.

c. Unsur storytelling pada buku 30 Ikon Kuliner Nusantara hanya sedikit dan belum dikembangkan ke media lain.

2) Depth Interview (Is Yuniarto)

a. Komik dapat menjadi media promosi yang baik asal tema dari komik relevan dengan merek yang dipromosikan.

b. Pemilihan media komik dengan subjek desain masak dianggap memiliki respon yang baik, karena komik dapat menjelaskan secara detil proses memasak.

c. Mengenai penetrasi pasar internasional, komik yang bertajuk tentang masakan indonesia dirasa oleh Is Yuniarto dapat diterima oleh pasar yang lebih spesifik dan menarik pembaca mancanegara.

\section{3) Studi Literatur}

a. Cara memasak, bahan dan cerita dibalik makanan.

b. Penggayaan komik.

c. Alur penceritaan.

d. Konsep Alur baca.

\section{4) Kuesioner}

a. Responden mancanegara terbukti tertarik untuk mengetahui cerita mengenai masakan dan kuliner Indonesia dengan $55.5 \%$ untuk tertarik, $32 \%$ untuk biasa saja dan $10.9 \%$ untuk tidak tertarik

b. Responden mancanegara mayoritas setuju bahwa informasi yang detil dapat diceritakan melalui media komik dengan total $84 \%$

c. Waktu dimana responden sering membaca komik adalah sekitar sebelum tidur dan ketika dalam istirahat singkat

d. Mayoritas responden menyukai genre Slice of life dengan jumlah tertinggi sebanyak $26 \%$

e. Mayoritas responden dari mancanegara setuju lebih mudah mendapatkan komik digital di negaranya dengan total $69 \%$ untuk setuju.

\section{KONSEP DAN APLIKASI DESAIN}

\section{A. Produk}

Masing-masing masakan yang ada pada 30 ikon kuliner nusantara memiliki kisahnya tersendiri yang menceritakan akulturasi budaya dan kebiasaan setempat. Hal itulah yang menjadi dasar dari perancangan komik digital ini. Komik digital dipilih karena dapat memaparkan informasi dengan bertahap, sedangkan pemilihan dalam bentuk digital berguna untuk mempenetrasi pasar internasional. Komik ini kemudian akan didistribusikan melalui platform komik digital Line Webtoon 


\section{B. Target Audiens}

Target utama dari Perancangan komik digital adalah Audien mancanegara. Karena media yang digunakan adalah komik dengan platform webtoon. Melalui penggunaan platform webtoon maka target audien bertambah menjadi pelajar remaja. Berikut kriterianya:

1. Laki - laki dan perempuan

2. Penggiat kuliner

3. Rentang usia (20 - 29 tahun)

4. Memiliki waktu luang ketika istirahat singkat.

5. Memiliki gadget dengan basis operasi Android

\section{C.Bagan Konsep Desain}

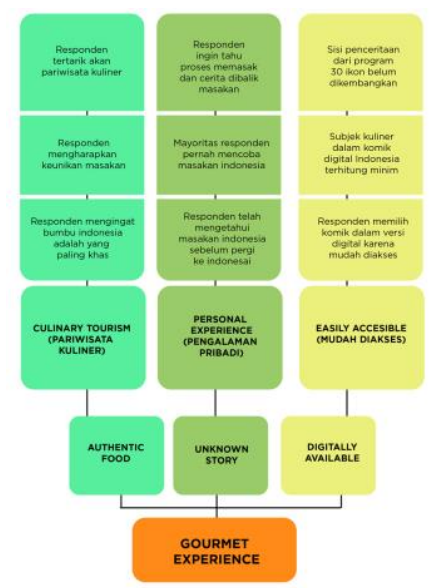

Gambar 1. Bagan Konsep Desain.

Dalam konsep "Gourmet Experience", cerita dalam komik akan berfokus pada pengalaman pribadi dari karakter asal luar negeri yang berwisata kuliner. Konsep penceritaan dihasilkan melalui hasil tanggapan responden yang mengatakan bahwa mereka memiliki pengalaman yang berbeda-beda serta memiliki antusiasme yang tinggi untuk mengenal kuliner Indonesia. Komik nantinya tidak hanya fokus membahas hanya pada konten ikon kuliner tapi juga pada pengalaman yang dirasakan turis dari mancanegara.

\section{Kriteria Konten}

\section{1) Konsep komunikasi}

Dalam konsep komunikasi akan dijelaskan strategi dalam menuturkan akan informasi masakan dan mengaitkannya dengan antusiasme dari audien mancanegara, berikut adalah kriterianya:

a. Karakter diatur menjadi 2 tipe, karakter serba tahu sebagai pemandu cara masak dan karakter utama yang tidak menahu tentang masakan Indonesia. Nantinya karakter pembantu akan mengajak dan membantu karakter utama untuk mengenal masakan Indonesia.

b. Karakter utama datang dari luar negeri dengan konfliknya sendiri-sendiri dengan tujuan dikaitkan dengan sejarah masakan agar terjadi relevansi dengan motif karakter.

c. Antusiasme ditunjukan karakter utama ketika belajar untuk mengenal masakan indonesia sebagai salah satu motif yang karakter utama harus selesaikan di dalam komik.

\section{2) Konsep Alur cerita}

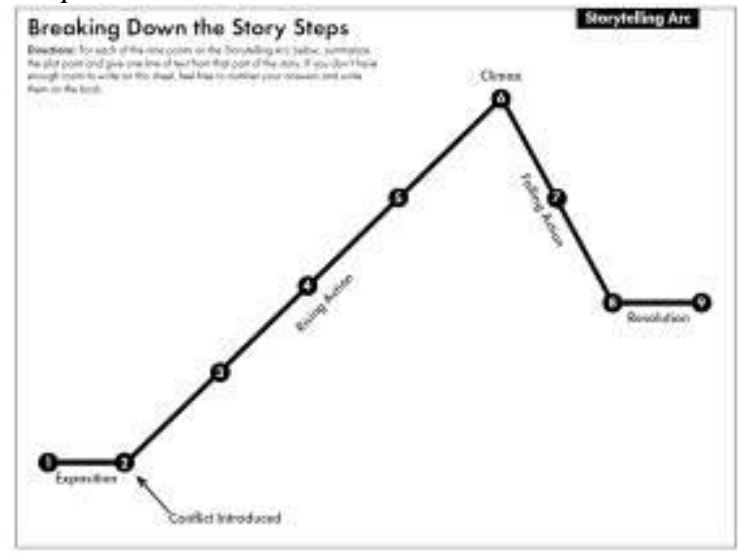

Gambar 2. Alur Pembabakan cerita.

Dalam menceritakan konten dari kuliner ada beberapa babak yang harus dilalui berikut penjelasannya:

a. Eksposisi

Karakter dari luar negeri diperkenalkan dengan motif mengapa ia berada di indonesia.

b. Konflik

Karakter bertemu dengan masalah yang berhubungan dengan motif utama mereka dan akan dipandu oleh karakter pendukung untuk menyelesaikannya.

c. Build $U p$

Bahan masakan, cara memasak serta kisah dibalik masakan diperkenalkan.

d. Klimaks

Puncak dari permasalahan, disini karakter utama berhasil memasak makanan yang ia buat.

\section{e. Falling Action}

Permasalahan mereda dan karakter mencicipi makanan yang ia telah buat.

f. Resolusi

Konflik sudah selesai dan karakter utama telah menyelesaikan motifnya.

\section{E. Kriteria Visual}

\section{1) Desain Karakter}

Kriteria penggambaran karakter dalam komik menggunakan penggayaan semi realis, dimana dengan penggayaan ini ekspresi antar karakter dapat dilebih lebihkan namun dapat menjaga penggambaran asli dari manusia. Didalam komik ini Penggambaran karakter utama mengikuti ciri khas orang dari berbagai negara seperti Cina dan Brazil. Berikut merupakan desain 3 karakter utama:

\section{a. Liu Wang}

Konsep dari Liu Wang adalah mahasiswa asal Cina yang tengah belajar di Indonesia. Karakteristik dari Liu adalah kulit terang kemerahan, hidung agak pesek dan rambut lurus rata samping. Liu Wang berpakaian tradisional dengan gaya kasual modern, Liu Wang adalah karakter utama yang ada pada seri Soto Ayam Lamongan.

\section{b. John Gabriel}

John Gabriel adalah karakter yang didesain sebagai pendatang yang berasal dari Amerika, dengan kulit putih kemerahan, jidat lebar dan rambut pirang. Di seri Klapertart John diposisikan sebagai suami dari Annabel Van Deer, yang 
diajak ke Manado untuk berkenalan dengan saudara sang istri. John akan belajar membuat Klapertart dengan bertanding melawan sang istri.
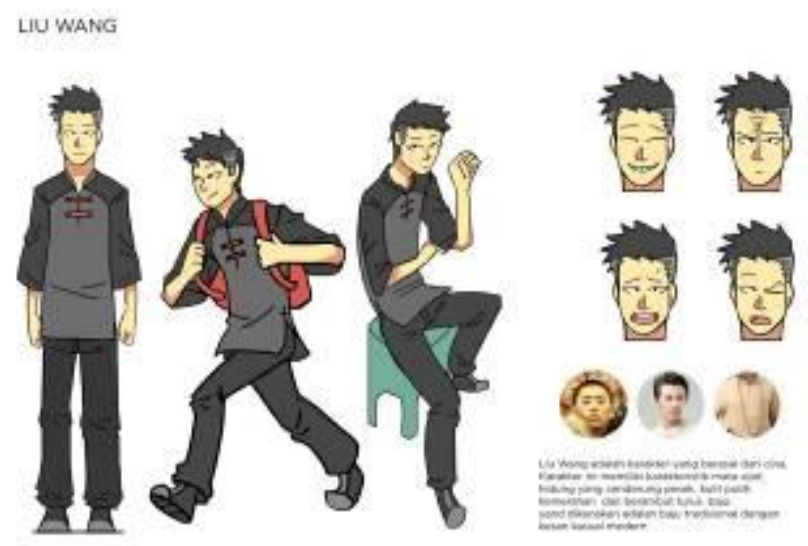

Gambar 3. Desain Liu Wang.

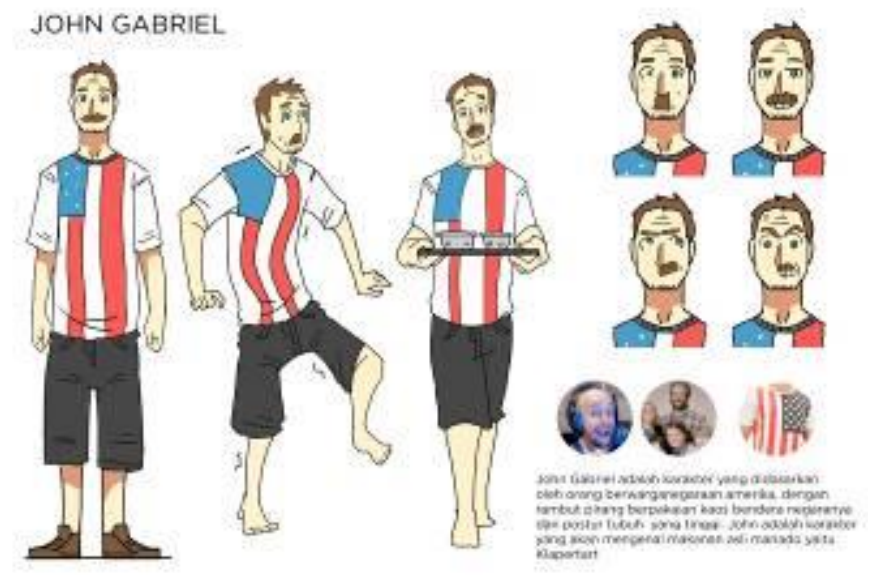

Gambar 4. Desain karakter John Gabriel.

\section{c. Lucas Rodrigo}

Lucas adalah karakter yang didasarkan pada orang berkebangsaan Brazil. Lucas di dalam seri Sarikayo diceritakan sebagai pemain bola pindahan asal Brazil yang bermain di tim lokal di Surabaya. Dia tengah berlibur di Padang hingga ia akhirnya ia tersesat dan ditolong oleh warga setempat.

2) Desain Alat makan dan tampilan masakan

Dalam mempersuasi audien bahwa makanan dalam komik terlihat nyata, penggambaran dari masakan dibuat lebih detail dari desain karakter. Berikut beberapa contohnya:

\section{a. Soto Ayam Lamongan}

Dalam membuat Soto agar memiliki kesan penuh yang harus diperhatikan adalah keramaian dalam mangkok Soto sendiri, dengan nasi, ayam, bihun serta telur yang ditata sedemikian rupa agar mangkok terasa penuh.

\section{b. Klapertart Manado}

Dalam menggambarkan klapertart hal yang harus diperhatikan adalah bagaimana cara agar isi dari tart dapat terepresentasikan didalam cerita.

\section{c. Sarikayo Minangkabau}

Dalam mengeksplorasi tampilan dan sudut dari Sarikayo, hal utama yang perlu diperhatikan adalah apakah penggambaran bahwa Sarikayo yang dikukus terlihat empuk untuk dinikmati.
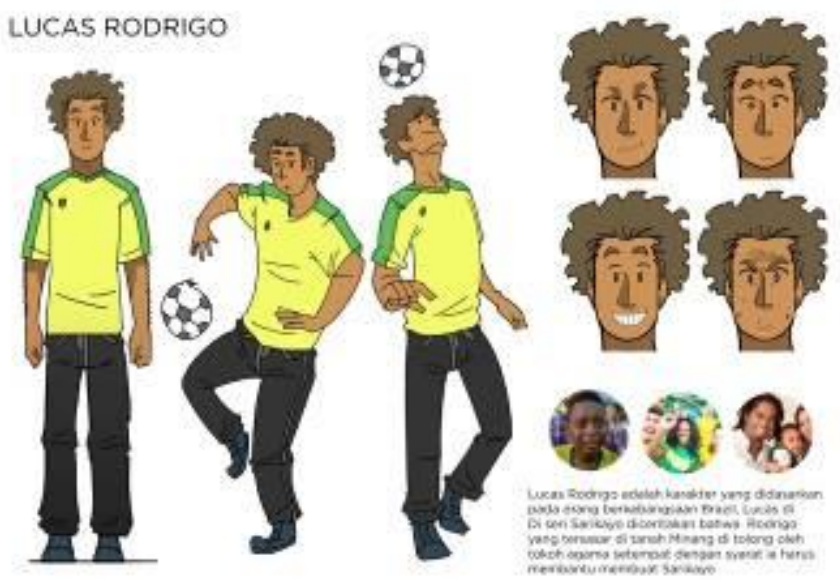

Gambar 5. Desain karakter Lucas Rodrigo.

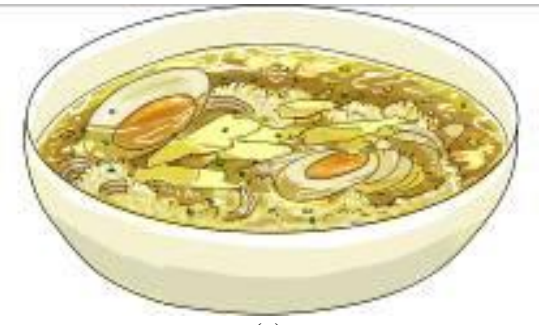

(a)

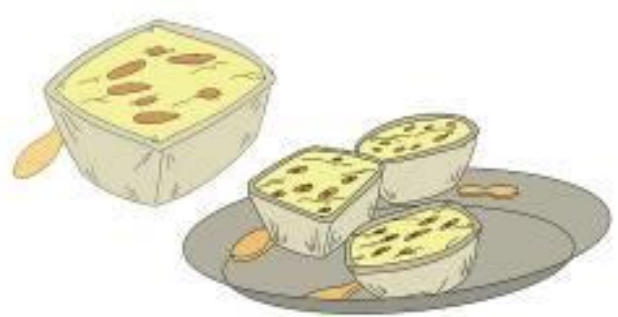

(b)

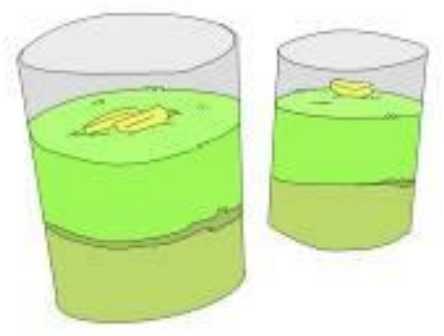

(c)

Gambar 6. a. Desain Soto Ayam, b. Desain Klapertart, c. Desain Sarikayo 3) Desain Environment

Pembuatan kriteria dari environment menggunakan latar tempat yang benar benar ada, contohnya seperti Rumah Woloan asal Manado dan Pasar Kopro di Jakarta Barat. 

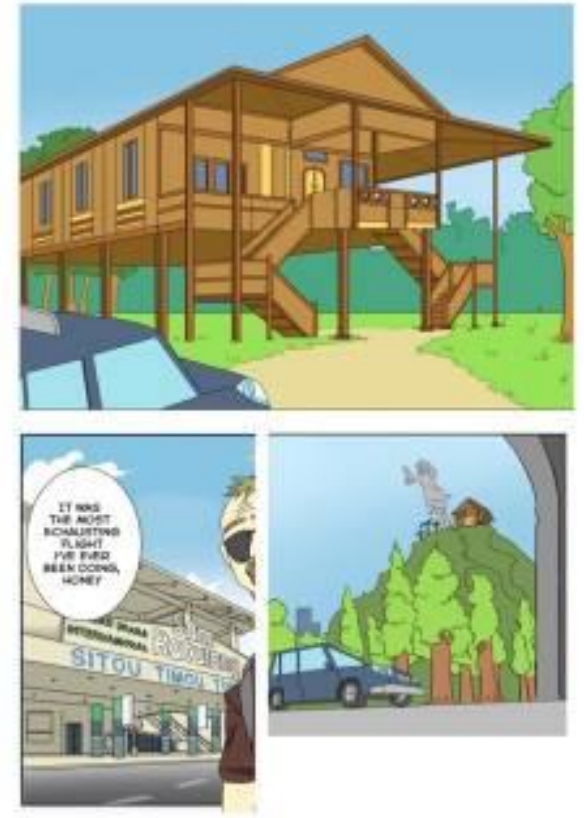

Gambar 7. Desain Environment.

\section{4) Contoh Hasil Halaman Komik}

Penyajian cerita didalam halaman komik berbeda beda mengikuti aturan yang telah ditetapkan dalam tiap babak. Ini bertujuan untuk pembaca mudah untuk mengikuti alur cerita dan infomasi yang diberikan.
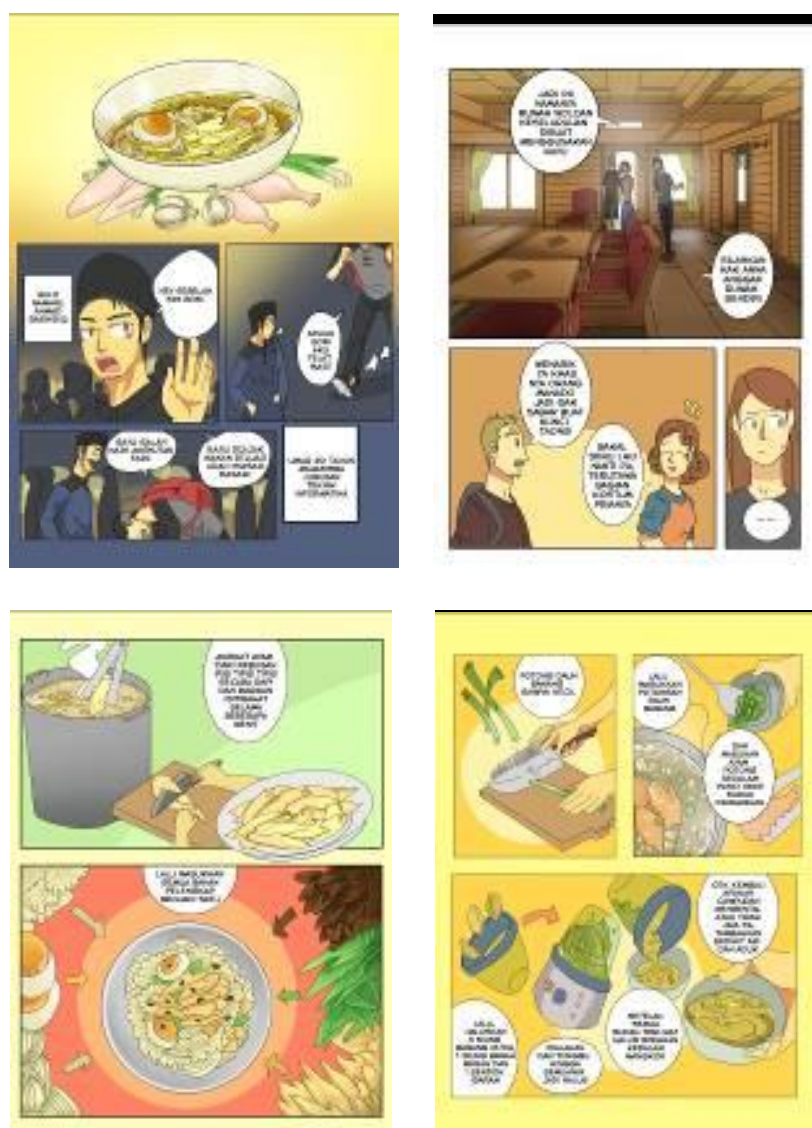

Gambar 8. Contoh halaman Komik

\section{5) Contoh Hasil Halaman Komik}

Dalam menggambarkan dan mempermudah pembaca dalam mengikuti alur cerita, didalam komik terdapat aturan yang digunakan dalam menata panel dan penggambaran dalam tiap halaman, berikut penjelasannya:

a. Percakapan antar karakter

Halaman ini menunjukkan percakapan antara karakter, disini penggunaan panel sebagai pemotong antara percakapan serta penjelas motif karakter. Semua visual di letakkan ke dalam panel tertutup.

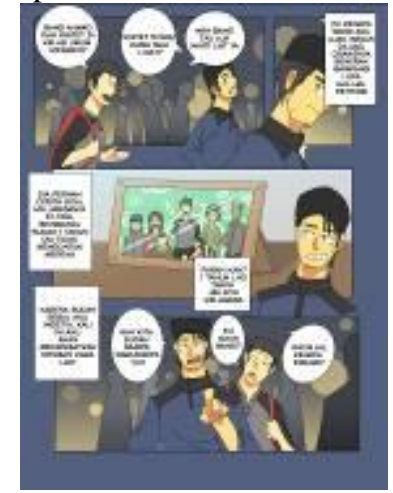

Gambar 9. Contoh percakapan antar karakter.

\section{b. Profil visual dari makanan}

Halaman ini menunjukkan transisi dari percakapan karakter menuju ke profil dari makanan terkait. Dalam halaman ini visual makanan tidak terikat dan terbatasi oleh panel.

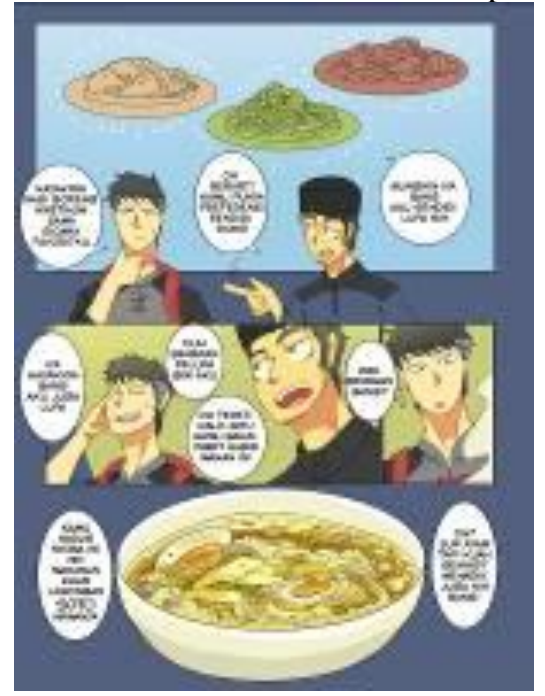

Gambar 10. Contoh halaman profil dari makanan.

c. Visual penjelasan sejarah makanan

Halaman ini menunjukkan karakter pemandu yang menjelaskan cerita tentang asal muasal masakan, kriteria visual pada halaman penjelas ini adalah:

1. Karakter pendukung diposisikan sebagai penjelas dan seakan akan dapat melihat informasi visual di belakangnya.

2. Karakter utama akan bertanya tentang keterkaitan sejarah masakan dengan masakan saat ini.

3. Penggambaran informasi visual dibuat tidak detail, termasuk penggambaran visual masakan juga akan di sederhanakan. 


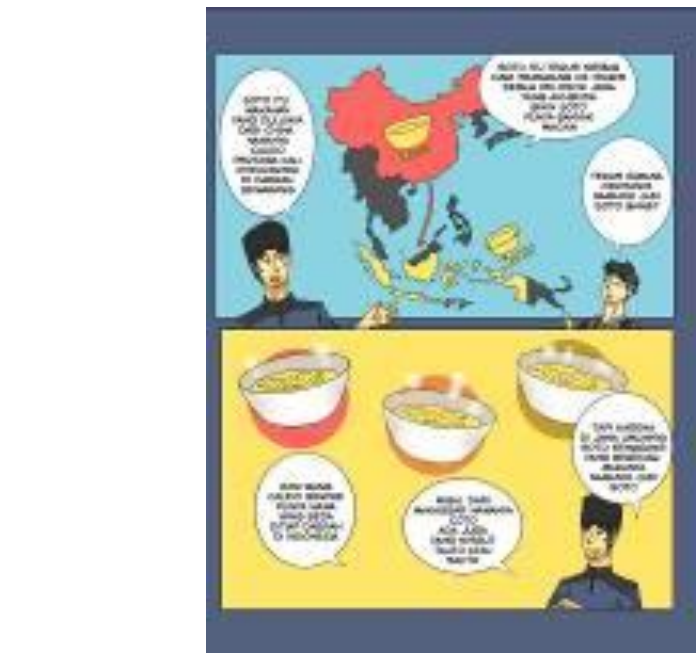

Gambar 11. Contoh halaman sejarah makanan.

d. Penyajian visual bahan dan peralatan masakan

Halaman ini menjelaskan bahan serta peralatan memasak, disini seluruh bahan tidak akan dibatasi oleh panel untuk memaksimalkan rana. Tiap bahan akan diberi balon dialog sebagai penjelas.

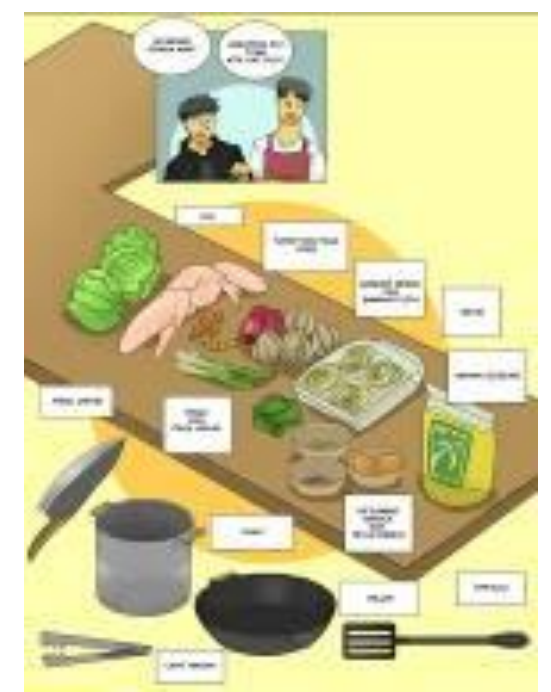

Gambar 11. Contoh halaman bahan makanan.

\section{e. Proses memasak}

Halaman ini menjelaskan visual dari proses memasak masakan, fokus visual akan ditujukan kepada bahan serta peralatan memasak. Keberadaan karakter hanya dibatasi pada tangan dan setengah badan.

f. Informasi tempat makan

Halaman ini adalah halaman terakhir yang menjelaskan informasi dimana makanan didapat. Disini akan dijelaskan visual tempat makan seperti gerobak pinggir jalan ataupun restoran makan. Balon dialog akan menjelaskan alamat dimana makanan dapat didapatkan.

\section{KESIMPULAN}

Melalui penelitian dan post test yang telah dilakukan selama jangka waktu perancangan, dapat disimpulkan beberapa hal untuk pengembangan komik digital ini seperti:

1. Komik sudah mampu menyajikan konten yang informatif dan deskriptif.

2. Penggambaran visual dari makanan sudah cukup mewakili dari makanan aslinya dan dapat mempersuasi pembaca.

3. Pengembangan komik dapat dilakukan dengan menyelesaikan seluruh 30 Ikon Kuliner kedalam format komik

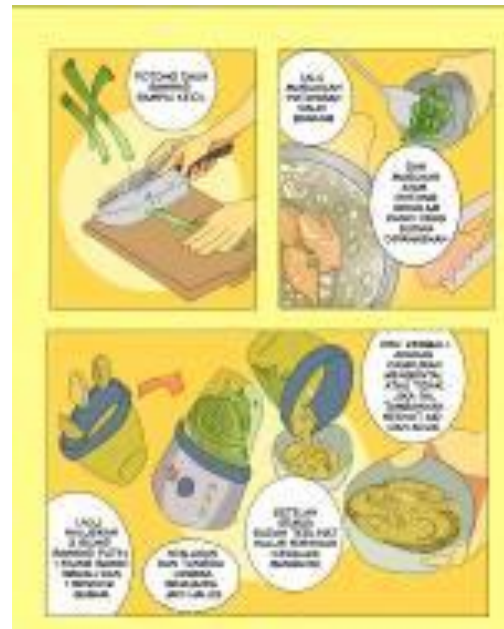

Gambar 12. Contoh halaman proses memasak.

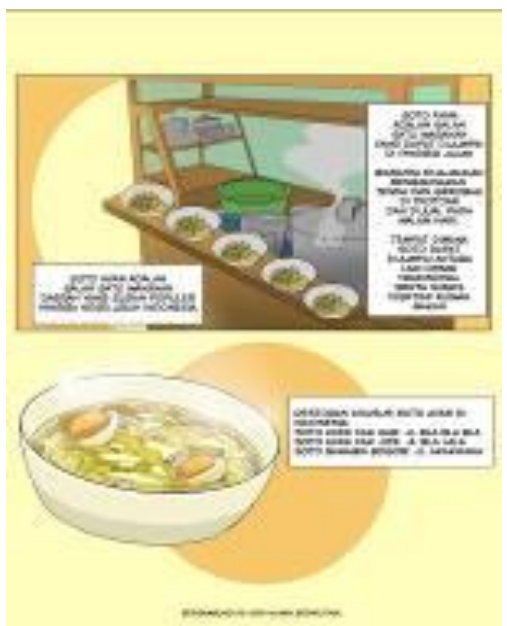

Gambar 13. Contoh halaman informasi tempat makan.

\section{DAFTAR PUSTAKA}

[1] S. Mccloud, Understanding Comicsthe invinsible Art”. 1993. 